\title{
Measurement of shell growth in oysters by weighing in water
}

Jay D. Andrews

Virginia Institute of Marine Science

Follow this and additional works at: https://scholarworks.wm.edu/vimsarticles

Part of the Aquaculture and Fisheries Commons

\section{Recommended Citation}

Andrews, Jay D., Measurement of shell growth in oysters by weighing in water (1961). Proceedings of the National Shellfisheries Association, 52, 1-11.

https://scholarworks.wm.edu/vimsarticles/1257

This Article is brought to you for free and open access by the Virginia Institute of Marine Science at W\&M ScholarWorks. It has been accepted for inclusion in VIMS Articles by an authorized administrator of W\&M ScholarWorks. For more information, please contact scholarworks@wm.edu. 
MEASUREMENT OF SHELL GROWTH IN OYSTERS

BY WEIGHING IN WATER ${ }^{1}$

\author{
Jay D. Andrews \\ Virginia Institute of Marine Science \\ Gloucester Point, Virginia
}

\begin{abstract}
Extensive use of a modification of the Havinga method of weighing oysters in water, using a Type $\mathrm{K} 7 \mathrm{~T}$ GD Mettler balance with suspension attachments, has shown that weekly weighing of numbered individuals reveals individual differences in rate of shell deposition which correlate with feeding, parasite infections, etc. The method is quick, sensitive, and accurate.
\end{abstract}

Methods of measurement of growth in oysters have become stereotyped despite widespread recognition of the inaccuracies involved. Usually one or more linear measurements, air weight, volume or some combination or derivative of these $\left(\mathrm{L} X \mathrm{~W}, \mathrm{~L}^{3}\right)$ is used. All of these are based on shell growth. No method has been developed for assessing meat growth except by sacrificing part of a population. This has led in growth studies to strong emphasis upon sampling of populations. But individuals in populations of oysters are notoriously variable. Being irregular in shape, oysters of the same weight can be quite variable in linear dimensions. Also, oysters with the same origin, history, and treatment can vary widely in weight at a given age (Butler 1925b).

Few studies have considered growth of individual oysters because representative specimens are difficult to choose and marking and measuring many individuals is tedious. The state of health of experimental oysters is seldom determined. (See Hopkins and Menzel 1952, Menzel and Hopkins 1955). Group samples of populations do not reveal the real parameters of environmental, hereditary, and health factors, and without individual records the techniques available for statistical analyses of variation are quite limited.

Another weakness of conventional methods of measuring growth is the long period required to obtain detectable changes in size. Even

1 Contribution from the Virginia Institute of Marine Science No. 110. 
in fast-growing species such as oysters, a month may be the minimum period for measurable changes in size.

Many changes in external environment and internal metabolism can occur in a month, and it becomes very difficult to determine and describe the conditions in which a certain growth occurred.

Another feature of most growth studies is the concern with practical applications in terms of how long it takes a certain stock to reach marketable size in given waters. Hopkins and Menzel (1952), and Hopkins, Mackin and Menzel (1953) have given excellent accounts of the factors which affect growth and yield in the Gulf of Mexico. McHugh and Andrews (1955) and Andrews and McHugh (1957) have discussed the same subjects for Chesapeake Bay. Butler (1952a), concerned with the practical problem of potential meat yields, uses the ratio of total volume of the oyster to shell volume as an index. Weights, volumes, and linear measurements are quite satisfactory for many field problems, but these same techniques have often been applied without adequate precision in basic studies of the causes, of variations in growth.

The purpose of this paper is to call attention to a method which permits quick and accurate measurement of shell-growth at short intervals. Daily shell growth was first demonstrated by Havinga (1928) by weighing oysters immersed in water. In this country Hewatt (1951 and 1952) first used the method in Louisiana studies in 1949 and. started its use in Virginia in 1951. Havinga's paper was not discovered by us until 1955, although the method was originally suggested to Hewatt by Dr. P. Korringa. In Virginia many years of weekly and bifweekly weighings indicate continuous calcification of shell throughout the year except in winter. The work of Wilbur and Jodrey (1952) with radioisotopes has shown that measurable shell deposition occurs in periods of only hours. Havinga's method measures total calcification of shell over short periods of time. Perhaps because the title emphasized growth rather than methods, Havinga's paper has seldom been referred to in the literature. Not only has the method been ignored but important conclusions about growth rates have been overlooked.

\section{DESCRIPTION OF METHOD}

The weight of live oysters suspended in water consists essentially of shell weight. The specific gravity of oyster meats is very close to that of salt water. Consecutive in-water weighings measure shell deposition. In-water weight of an oyster is approximately half the weight in air. 
The mechanics of handling oysters for weighing in water are quite simple due to the oyster's ability to maintain watertight closure for long periods. Nevertheless, precaution should be taken to keep oysters in water prior to weighing except for brief periods of transfer and cleaning. Only weak oysters and those numbed by cold are slow to close when disturbed. At Gloucester Point oysters are held in trays suspended in the York River. Before being lifted, trays are jiggled under water to ensure closure of oysters. Oysters selected for weighing must be free of injuries and crevices which prevent tight closure. This has been no problem with young oysters which are by far the best subjects.

Selection and preparation of oysters is important. Oysters with crumbly shells and those infested with shell-boring organisms should be avoided. If infested oysters must be used, they should be treated with brine solution or other chemical solutions for removal of shell pests (MacKenzie and Shearer 1961, Shearer and MacKenzie 1961). In our experiments, fairly large oysters of $15 \mathrm{~g}$ (30 g in air) or more have been used for disease studies. However, small young oysters are more sensitive indicators of environmental changes, since growth rate decreases rapidly with increase in size (Andrews, unpublished data). Also, young oysters in the Chesapeake area are usually relatively free of diseases, hence spat and yearlings provide the most satisfactory material for most experiments .

All fouling organisms and loose shell must be removed initially and oysters must be recleaned before each weighing. This has not been difficult except for short periods in spring and fall when barnacle sets are abundant. Weekly weighing minimizes the cleaning problem. It is most important to remove all calcareous growth. Breakage of new "bill" or "shoot" should be avoided but is not important, because calcium deposition is slight in new fragile shell.

Oysters are given individual numbers in various colors of "Mark-tex" ink after quick-drying the shells with a fan. The feltnib quick-dry marking pens now common in drug stores have not been tried extensively but appear to be even better.

Constant conditions for weighing should be sought. Each investigator should note small errors from temperature, salinity and volume changes in the vessel used for submersion. Oysters should be kept in running water throughout preparation to maintain ambient temperatures. Sharp changes in water temperatures may cause air bubbles to form on oysters. At Gloucester Point ambient salinities of the York River are used throughout the weighing process for weekly changes are usually small. Complete submersion is essential. 
At first a triple-beam balance was adapted with a grid pan suspended in a large finger bowl. Now a Mettler balance (Type K7 T GD) is-used with suspension-attachments-which can be tared for direct reading of oyster weights (Fig. 1). Oysters can be weighed almost

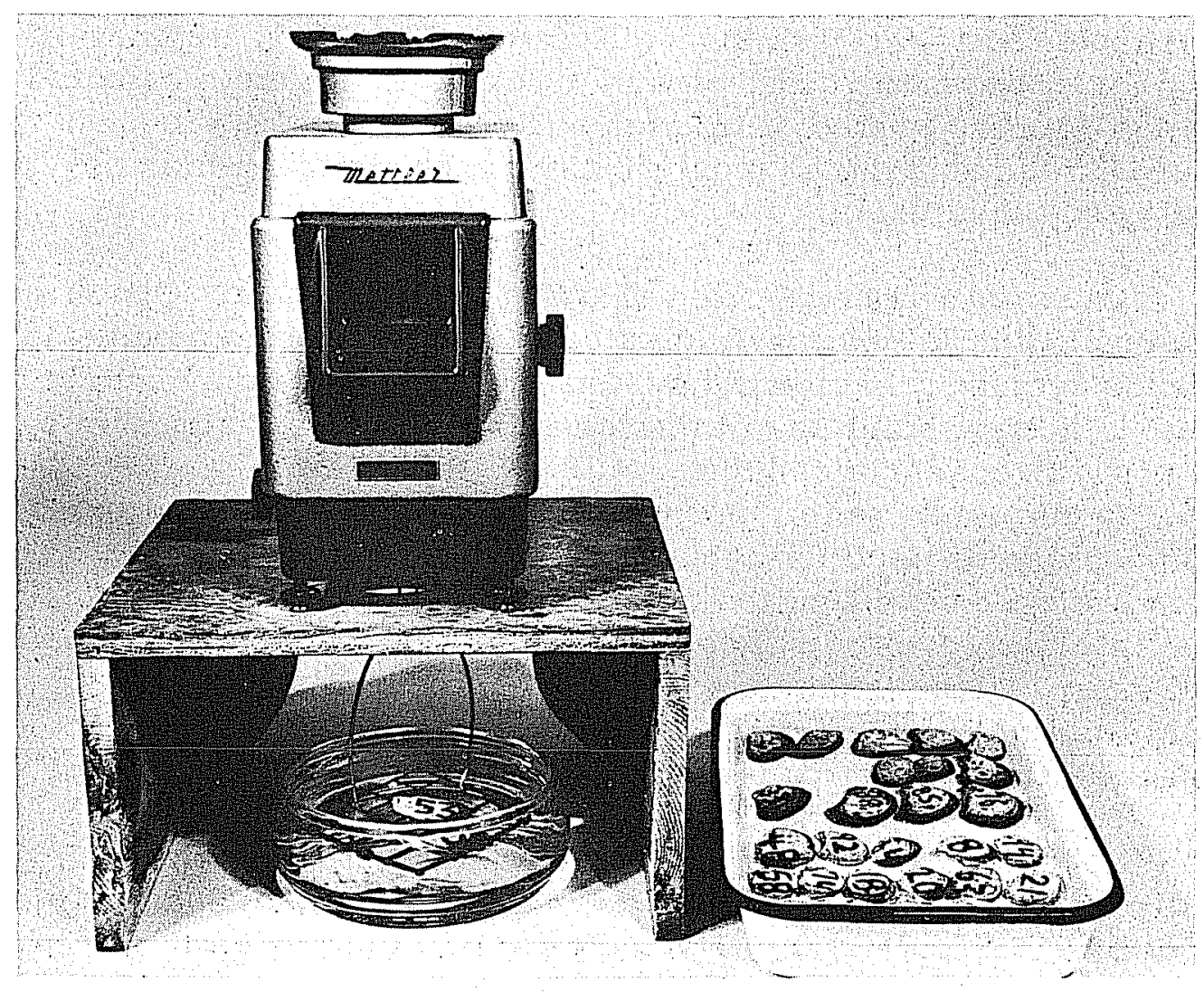

Fig. 1. Arrangement of Mettler scale for suspension weighing in water. Suspension equipment is tared permitting direct reading of oyster weights.

as rapidly as one linear measurement can be made. Immersed weighing is less convenient in the field although the triple-beam balance has been used on docks.

Weights are estimated to the nearest $0.01 \mathrm{~g}$ on a scale which reads in $0.1 \mathrm{~g}$. Weights can be replicated easily within $0.05 \mathrm{~g}$ even after oysters have been removed from water for some time. A change in weight of less than $0.1 \mathrm{~g}$ in a week has become one indicator of "sick" oysters in my work. "Good" growth for a $15 \mathrm{~g}$ oyster in water 
is $1 \mathrm{~g}$ per week. The regularity of increase in weights from week to week and the persistence of healthy oysters in depositing shell throughout the warm season is illustrated in Fig. 2. This shows a

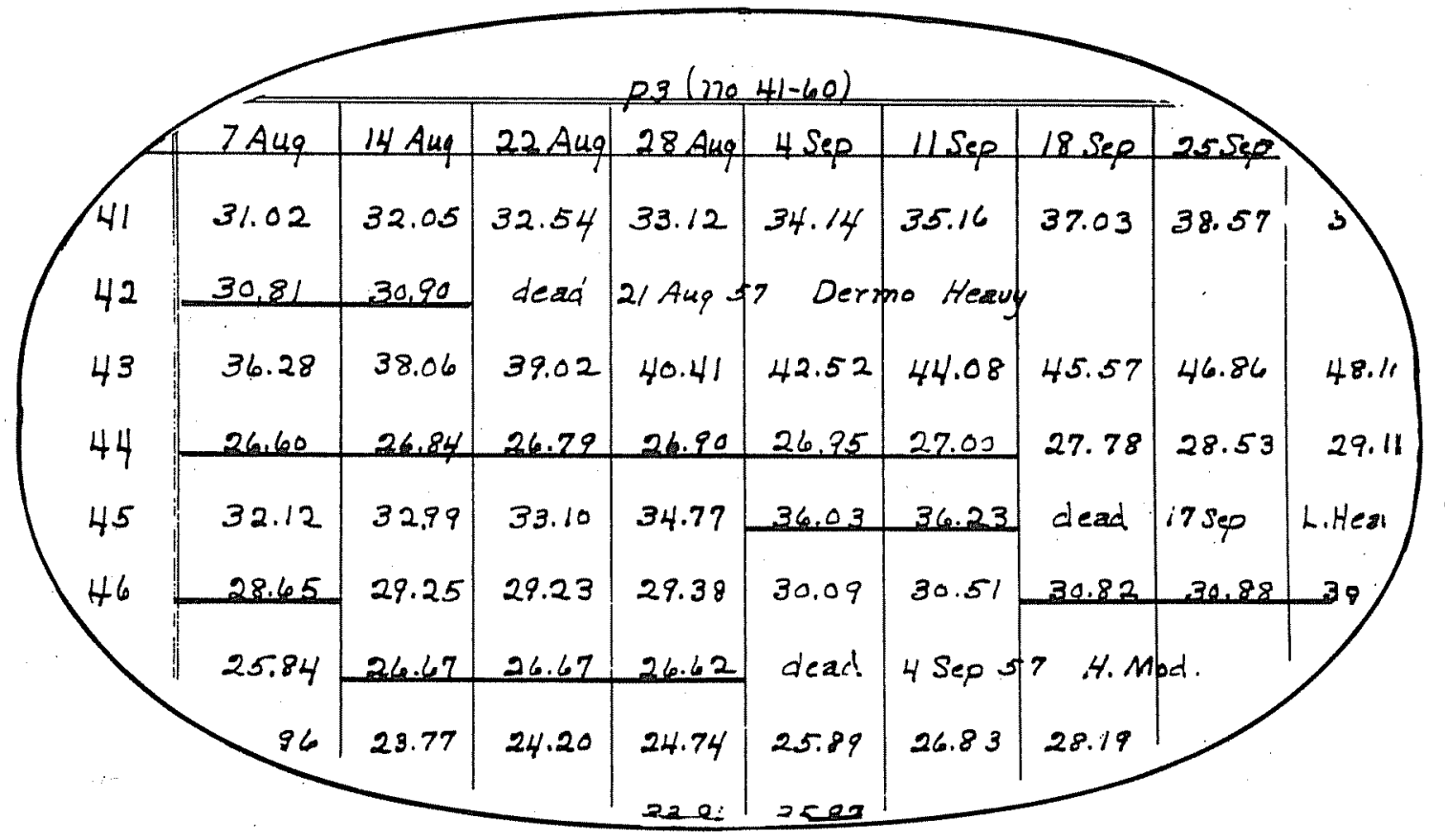

Fig. 2. Example of data sheet for weighing oysters in water. Underlining indicates periods of "sickness" as indicated by lack of growth.

portion of a data sheet in late summer when Dermocystidium (Andrews and Hewatt 1957) was active. Growth of several individual oysters is shown in Fig. 3 to indicate continuity of growth throughout the warm season and variation in patterns with the health of oysters. Further examples can be found in Hewatt (1951). 


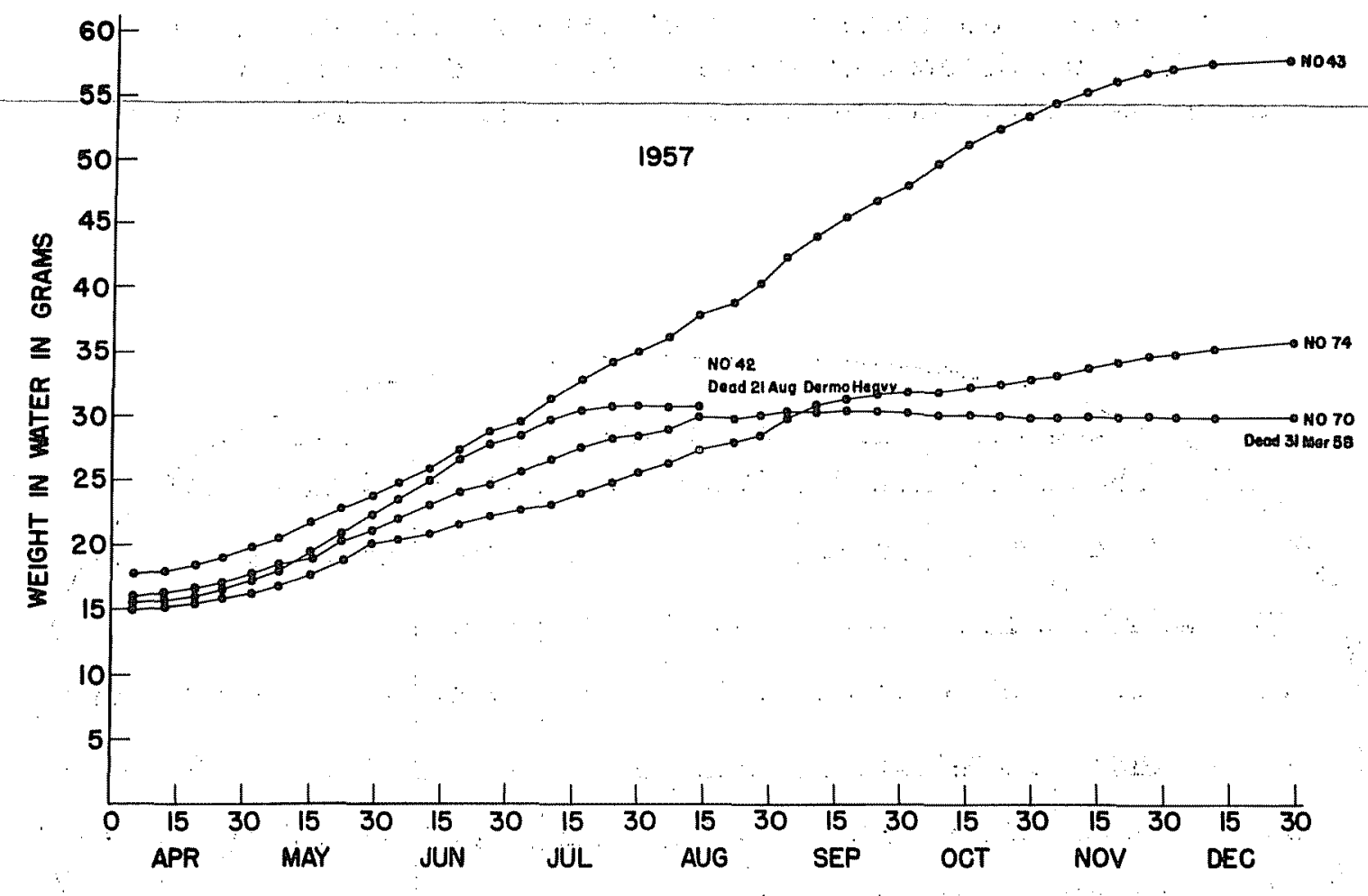

Fig. 3. Progressive weekly weights of four oysters: fast and slow growers, and two" "sick" oysters. No. 74 was probably sick too but did not die.

\section{USES OF. THE IN-WATER WEIGHING TECHNIQUE}

\section{Measurement of Short-term Growth}

Short-term measurement of growth is the most important advantage of the method. The environmental factors (internal and external) regulating growth of oysters are continually changing. The shorter the period of growth which can be measured; the easier it is to describe the conditions which produced this growth. One week has proven to be an adequate period for useful sorting of oysters by their growth potentials. Havinga's method does not equal radioisotope methods in sensitivity and shortness of interval to obtain measurable growth (Wilbur 1960), but does permit observations of growth under more favorable and more natural conditions. In contrast, linear measurements and air welghts may be meaningful only by months or seasons, and the sensitivity decreases with age and size of oysters even more rapidly than for in-water weighing. 
Assessment of Variations in Growth Between Individuals

Most investigators are aware of wide variations in growth between individual oysters (Butler 1952b and Walne 1958). Yet individual oysters are often used to measure pumping rate, feeding rate and other physiological characteristics with no more check on growth potential than that provided by the investigator's intuition. Variation in a group can not be adequately measured without individual records.

Detection of "Sick" or Weak Oysters

Hewatt (1951) and Menzel and Hopkins (1955) demonstrated that oysters sick with infections of Dermocystidium marinum stopped increasing in weight and eventually died. I have successfully used cessation of shell growth as a basis for separating sick oysters from healthy ones where other diseases and parasites are involved as well as in Dermocystidium studies.

\section{Effects of Diseases and Parasites on Oysters}

The effects of experimental and natural infections can be followed by weight changes in oysters since shell deposition seems to be closely linked to health and well-being. See Menzel and Hopkins (1955). However, physlological states may occur in healthy oysters in which shell deposition does not Dccur. Individuals with no apparent cause for lack of growth have been suspected of harboring undiagnosed disease.

\section{Effects of Various Treatments}

The time is fast approaching when oysters will be exposed to various chemicals and treatments designed to control predators and diseases. Salt brine, fresh water, chlorinated hydrocarbons, and heavy oils are being used or proposed already. Injuries, food combinations, pollution, and many other conditions of stress or benefit can probably be followed in terms of oyster reaction by the in-water weighing method.

\section{Index of Suitability of Environment}

Oysters are among the most efficient filter feeders in terms of quantity of water processed. As a sampling device for measuring plankton content of water, they may be as useful as nets and pumps. Although efficiency of collection is high, the kinds and quantities of 
food used are not so well understood. Nevertheless, a group of oysters is a sensitive indicator of quality of the environment as expressed by in-water welghts. Two or three weighings over a period of several-weeks will give a useful evaluation of currently existing conditions for oyster growth in an area. Many kinds of comparisons of environment may be possible in respect to growth, fattening, pollution, and other factors. For example, in 1961 oyster growth in the York River was stopped for about one month in mid-summer during a consplcuous and extensive "red tide" bloom.

\section{A Check on Experimental Conditions}

Weighing in water is a: scientist's tool rather than a practical measure of growth and yield. It is being used at the Virginia. Institute of Marine Science to check laboratory conditions in experiments such as conditioning for spawning, suitability of aquarium habitats, studies of fecal and pseudofecal deposition, and food studies. "Control" groups can be held in natural waters for comparison. It appears that oysters without food do not deposit appreciable amounts of shell.

\section{DISCUSSION}

Havinga (1928) anticipated many of the uses of the weighing techniques and his paper should be consulted by anyone using the method. A very careful description of methods is included. I concur in his observations about the irregularity of fresh shoot or bill formation and its relative unimportance as a sign of oyster growth" I" have not found it necessary to be as cautious as Havinga was, about handling oysters. I have observed no interference with growth from necessary handling. The few hours of interruption while the oysters were being weighed or numbered merely deprived them of that time for feeding.

It is important to realize that oysters thicken their shells throughout life by additions to the entire inner surface of the valves. This is apparently much less true of many other pelecypods in which the valves remain almost uniform in thickness with most additions of new shell at the edges. Even in oysters Wilbur and Jodrey (1952) provide evidence that calcification is more rapid near the borders of the valves, but the adjustments of shell shape discussed by Korringa (1951) and Galtsoff (1954) may modify this pattern. Injuries may also alter the rate and pattern of shell deposition. "In Virginia no change of weight occurs between late December and early April when temperatures are usually below $5^{\circ} \mathrm{C}$. However, Galts off (1958) reports that injuries or obstructions will induce shell repairs in mid-winter at very low temperatures. 
The technique of weighing in water has been tried with hard clams, Mercenaria mercenaria, without much success. Calcification is apparently much slower than in oysters. For example, hard clams held in trays without substratum become infested with Polydora websteri and are incapable of covering the resulting mud blisters satisfactorily. The weighing method requires rapid daily deposition of calcium salts and water-tight closure of shells. The oyster exhibits these characteristics to a high degree. Other tightly-closing mollusks should be tried.

Although the capacity of oysters to repair shells appears to be large, there have been no striking examples of exceptional rates of shell deposition. There is no indication that the usual, rates of deposition of fast-growing oysters can be exceeded-even if repair is urgent. The fastest rates of deposition have been observed in apparently healthy oysters with continuous growth over many weeks.

My observations indicate that oysters deposit shell only when feeding satisfactorily. Oysters held in aquaria with limited food do not add enough shell to be measured by the weighing technique. Orton's observations (1925) of continued shell growth in the absence of food probably referred to production of new bill, which is primarily organic in composition. The Havinga technique provides a means of determining the total deposition of calcium salts for rather short periods in favorable environments. This should provide a quantitative base line for investigations of calcification in mollusks.

It is Important to determine by radioisotope methods whether shell deposition is intimately related to food metabolism. Observations that shell deposition can be interrupted by sickness, failure to pump, or lack of food, suggest a rather close tie between calcification and food collection. Collection by separate techniques of concurrent data on pumping rates, amount of food collected and weights in water should provide new insights into oyster metabolism. Since diapedesis (emigration of leucocytes to outer surfaces) is frequently observed in oysters held out of water for some time, there may be an excretory function too in shell deposition.

Recent work (Bevelander 1952) indicates that considerable confusion exists as to the source of calcium salts for shell deposition. It is recognized that the amount deposited is too great to be stored in tissues or to be derived from food alone. However, when food is being collected, large volumes of water are being passed over and through the tissues providing ample opportunities for absorption 
or diffusion of calcium salts in marine species. It would be quite surprising if shell deposition occurred to any extent while oysters are closed.

In summary, weighing in water is a sensitive technique for measuring individual variations in growth over short periods. The method permits selection of optimal conditions and the most satisfactory individuals for experimental studies. The disadvantages are failure to indicate meat quality, necessity for cleaning oysters carefully before each weighing, and a lack of usefulness in studying old eroded oysters.

\section{REFERENCES CITED}

Andrews, J.D. and Hewatt, W. G. 1957. Oyster mortality studies in Virginia. II. The fungus disease caused by Dermocystidium marinum in oysters of Chesapeake Bay. Ecol. Monogr . 27:1-25.

Andrews, J.D. and J. L. McHugh. 1957. The survival and growth of South Carolina seed oysters in Virginia waters. Proc . Nat'1 Shellfish. Assoc . 47 (1956): 73-82.

Bevelander, G. 1952. Calcification in Molluscs. III. Intake and deposition of $\mathrm{Ca}^{45}$ and $\mathrm{P}^{32}$ in relation to shell formation. Biol. Bull. 102:9-15.

Butler, P.A. 1952a. Shell growth versus meat yield in the oyster C. virginica. Natl Shellfish. Assoc. Conv. Add. 1952: 157-162.

Butler, P.A. 1952b. Seasonal growth of oysters (C. virginica) in Florida. Nat'l Shellfish. Assoc. Conv. Add. 1952:188-191.

Galtsoff, P.S. 1954. Recent advances in the studies of the structure and formation of the shell of Crassostrea virginica. Proc . Natl Shellfish. Assoc. 45:116-135.

Galtsoff, P.S. 1958. Personal Communication.

Havinga, B. 1928. The daily rate of growth of oysters during summer. J. du Conseil 3:231-245.

Hewatt, W. G. 1951. An oyster feediny experiment. Texas A. \& M. Res earch Foundation Project Nine Report, 14 p. 
Hewatt, W. G. 1952. An oyster feeding experiment. Natl Shellfish. Assoc. Conv. Add. 1952:192-193.

Hopkins, S. H. and R. W. Menzel. 1952. Methods for the study of oyster plantings. Natl Shellfish. Assoc. Conv. Add. 1952: 108-112.

Hopkins, S.H., J.G. Mackin and R. W. Menzel. 1953. The annual cycle of reproduction, growth and fattening in Louisiana oysters . Natl Shellfish. Assoc. Conv. Add. 1953:39-50.

MacKenzie, C. L., Jr. and L.W. Shearer. 1961. Chemical control of Polydora websteri and other annelids inhabiting oyster shells. Proc. Natl Shellfish. Assoc. 50: 105-111.

McHugh, J . L . and J. D. Andrews . 1955. Computation of oyster yields in Virgina. Proc. Natl Shellfish. Assoc. 45 (1954): 217-239.

Menzel, R. W. and S. H. Hopkins. 1955. The growth of oysters parasitized by the fungus Dermocystidium marinum and by the trematode Bucephalus cuculus. J . Parasitol., 41:333-342.

Orton, J.H. 1925. The conditions of calcareous metabolism in oysters and other marine animals. Nature 116:13.

Shearer, L. W. and C. L. MacKenzie, Jr. 1961. The effects of salt solutions of different strengths on oyster enemies. Proc. Natl Shellfish. Assoc. 50:97-103.

Walne, P.R. 1958. Growth of oysters (Ostrea edulis L.). J. Mar. Biol. Assoc. U.K. 37:591-602.

Wilbur, K. M. 1960. Shell structures and mineralization in molluscs . In Calcification in Biological Systems. AAAS Publ. 64, pp. $15-40$.

Wilbur, K. M. and L. H. Jodrey. 1952. Studies on shell formation. I. Measurement of the rate of shell formation using $\mathrm{Ca}^{45}$. Biol. Bull. 103:269-176. 